\title{
Transsphenoidal pituitary adenoma resection: do early post-operative cortisol levels predict permanent long-term hypocortisolism?
}

\author{
Vicki M. Butenschoen ${ }^{1}$ (D) Alexander von Werder ${ }^{2} \cdot$ Stefanie Bette $^{1,3} \cdot$ Veronika Schmette $^{1} \cdot$ Nina Schwendinger $^{1}$. \\ Bernhard Meyer ${ }^{1} \cdot$ Jens Gempt ${ }^{1}$
}

Received: 19 April 2021 / Revised: 31 August 2021 / Accepted: 7 September 2021 / Published online: 20 September 2021

(c) The Author(s) 2021

\begin{abstract}
Transsphenoidal surgery provides a minimal invasive treatment for pituitary adenoma. Our aim is to evaluate the endocrinological outcomes after adenoma resection focusing on the corticotroph function, and to identify prognostic factors for an impaired hypothalamic-pituitary-adrenal-axis function (HPA) and the reliability of postoperative early morning serum cortisol measurements. We performed a retrospective analysis of all patients treated for pituitary adenoma from April 2006 to January 2019 in our neurosurgical department. Pituitary function was assessed pre- and postoperatively as well as at 6 weeks to 12 weeks and at 1-year follow-up. Two hundred eleven patients were included. Nine percent of the patients recovered from a preoperative adrenal insufficiency, 10.4\% developed a new need for hormone substitution, and a long-term deficiency of the hypothalamic-pituitary-adrenal-axis was observed in 30.9\%. Cortisol measurements 5 days after surgery had a lower area under the curve (AUC) than cortisol levels detected after 6 to 12 weeks (AUC 0.740 vs. AUC 0.808 ) in predicting an intact corticotrope function. The cut-off value determined for cortisol measured after 6 weeks was $6.95 \mu \mathrm{g} / \mathrm{dl}$ (sensitivity of $94 \%$, specificity of $68 \%$ ). Postoperative early morning cortisol levels seem to be less sensitive and specific in predicting long-term corticotroph function than measurements after 6 weeks and 1 year, emphasizing the importance of endocrine follow-up testing.
\end{abstract}

Keywords Pituitary adenoma $\cdot$ Transsphenoidal surgery $\cdot$ Hypocortisolism

\section{Introduction}

Tumors of the pituitary gland account for approximately $15 \%$ of all intracranial tumors and the benign pituitary adenoma represent the most common encountered entity (up to 85\%) $[8,39,42,43]$ of all sellar lesions. The transnasal transsphenoidal (TSS) operative resection of sellar tumors has firstly been described in 1907 by Schlofer et al. and further developed by Cushing et al. in 1909 [5, 27, 40]. Nowadays, TSS is considered the most appropriate and initial approach for treatment of tumors of the pituitary gland [40, 41]. It can reduce hospital costs by shortening the length of hospital stay (LOH) and presents a safe and effective surgical

\section{Jens Gempt}

Jens.Gempt@tum.de

vicki.butenschoen@tum.de

Alexander von Werder

Alexander.Werdervon@mri.tum.de

Stefanie Bette

stefanie.bette@uk-augsburg.de

Veronika Schmette

vroni.schmette@gmx.de

Nina Schwendinger

Nina.Schwendinger@tum.de

Bernhard Meyer

Bernhard.Meyer@tum.de
1 Department of Neurosurgery, Klinikum Rechts Der Isar, Technical University Munich, Ismaningerstr. 22, 81675 Munich, Germany

2 II. Medizinische Klinik Und Poliklinik, Klinikum Rechts Der Isar, Technische Universität München, Munich, Germany

3 Abteilung Für Diagnostische Und Interventionelle Neuroradiologie, Universitätsklinikum Augsburg, Augsburg, Germany 
resection option with fewer complications and better clinical out-comes than the transcranial route [44, 45].

Pituitary adenoma patients may present with mass effect and lead to a compression of the optic chiasm with visual field defects and impaired visual acuity. As the pituitary gland plays a pivotal role in hormone regulation, adenomas can lead to an impaired adrenal pituitary function or hormone hypersecretion such as Acromegaly or M. Cushing due to a hypersecretion of growth hormone $(\mathrm{GH})$ or adrenocorticotropic hormone (ACTH).

Most important is the preservation of an intact hypothalamic-pituitary-adrenal-axis (HPA) regulating in a circadian rhythm and depending on physical stress levels cortisol release through the stimulation of ACTH [15]. Therefore, patients need to be monitored closely for symptoms of hypocortisolism, the most dangerous and life-threatening complication of pituitary deficiency [28], presenting with impaired metabolism such as anorexia, fatigue, hypotension and nausea, and potentially leading to the lethal adrenal crisis including shock and volume depletion called Addison's crisis [18, 33]. Many studies have focused on the optimal serum cortisol threshold (or cut-off value) to determine whether a patient suffers from hypocortisolism or not, and to prevent patients from adrenal corticotropic deficiency by substituting hydrocortisone [3, 17, 29, 31, 43]. Oral hydrocortisone, the generic pharmaceutical name of cortisol, has a plasma half-life of $1.5 \mathrm{~h}$, a biologic half-life of 8-12 h, and a glucocorticoid potency of $0.8[13,36]$. Minimum serum values range from 4 to $20 \mu \mathrm{g} / \mathrm{dl}$ (morning serum level, $1 \mu \mathrm{g}$ / $\mathrm{dl}=27,59 \mathrm{nmol} / \mathrm{l}$ ), but only few conducted studies have been performed and published with a long enough follow-up to establish cortisol supplementation criteria [24, 28, 43].

The optimal cut-off value of morning fasting cortisol level plays a pivotal role in determining the risk for hypocortisolism and needs to be detected early in order to start the optimal treatment, but also to avoid hydrocortisone overreplacement to minimize possible side effects like osteoporosis and impaired glucose tolerance [2, 37]. Regular follow-up testing of the fasting morning cortisol levels is therefore performed before and after surgery, as well as at neurooncological follow-up appointments.

In our study, we focus on the diagnostic value of direct postoperative and follow-up cortisol measurements and possible influencing prognostic factors to detect pituitary hypocortisolism due to surgery-related injury of the pituitary gland, in order to provide the most reliable timing and cortisol cut-off value to predict long-term need of hydrocortisone replacement therapy.

\section{Methods}

We retrospectively analyzed all patients treated via TSS for histologically proven pituitary adenomas from April 2006 to January 2019 in our neurosurgical department in a tertiary referral hospital by two senior attending neurosurgeons.

Inclusion criteria were diagnosed hormone-inactive adenoma of the sellar region, complete data available including complete clinical and endocrinological data such as cortisol serum levels, age $>18$ years, minimum endocrinological and clinical follow-up of 1 year after surgery, and surgery performed via a transsphenoidal approach. Patients with other tumors than adenoma of the sellar region and prior intake of prednisolone were excluded from our study. Patients presenting with pituitary apoplexy were included if complete endocrinological testing was performed before surgery and adenoma tissue was identified in the specimens sent to histopathology.

We retrieved demographic factors from our archives such as gender, age, and Karnosfky performance scale (KPS), as well as comorbidities from patient files, pre- and postoperative imaging (magnetic resonance imaging MRI, computed tomography CT) for extent of resection (EOR, gross total resection GTR vs. partial resection (PR)), and perioperative hormone levels of basal cortisol ( $\mu \mathrm{g} /$ dl) gained from the patient in the morning (fasting serum values, cobas 8000 analyzer Roche). Urinary free cortisol levels were not included for analysis. Information on the operation performed included microscopic vs. endoscopic approach, length of operation (mean time in minutes), and intra-operative complications (cerebrospinal fluid CSF leak, major bleeding). The minimum clinical and endocrinological follow-up time was 1 year, and patients were monitored for anterior and posterior pituitary deficiency and need for hormone substitution after TSS. Corticotropic deficiency was also diagnosed when the patient presented with clinical symptoms of hypocortisolism after withdrawing or reducing the oral hydrocortisone substitution, even if the basal morning serum cortisol level was above a defined threshold.

Statistical correlation analyzes were performed using the IBM SPSS software (Version 26.0.0.0). Multivariable analyses were conducted using ANOVA and $\mathrm{Chi}^{2}$ testing. Cut-off values were determined using the receiver-operator curve (ROC), area under the curve (AUC), and the YoudenIndex [46]. Correlation analysis was performed using the Spearman coefficient, and a $p$-value $<0.05$ was considered significant.

The presented study meets the ethical standards outlined in the Declaration of Helsinki, ethics approval was obtained before performing the analysis (Ethikkommission der Technischen Universität München, Prof. Dr. Schmidt), and the positive vote was registered under the number 231/20-S. Due 
to the retrospective nature of the study, informed consent was waived in accordance with the Ethics Commission. All methods were carried out in accordance with relevant guidelines and regulations.

\section{Results}

\section{Patient population}

We were able to identify 429 patients who were treated via the transsphenoidal approach for tumors of the sellar and parasellar region from April 2006 to January 2019 in our clinical neurosurgical department. Sixty-two patients with hormone-producing adenoma causing Acromegaly and M.
Cushing were excluded due to their distinct preoperative cortisol levels (Fig. 1). Fifty-nine patients were excluded due to histopathological diagnosis of tumors other than pituitary adenoma (meningioma, Rathke's cleft cysts, hypophysitis) due to their distinct clinical outcome. In total, 97 patients were lost to follow-up endocrinological data at 1 year.

We were able to include 211 patients for further analysis. Comparing the numbers over the years, we observed a trend towards increasing numbers of surgeries performed for transnasal pituitary adenoma resection (number of cases included between 2006 and 2012, $n=72$; 2013-2019, 139 cases).

Median age was 56 years with a range of 20-86 years. Sixty percent $(n=127)$ were male and $40 \%(n=84)$ female patients. Median preoperative KPS was $90 \%$ (range
Fig. 1 Flowchart describing the number of patients meeting the inclusion and exclusion criteria and showing the number of patients included for analysis $(n=211)$

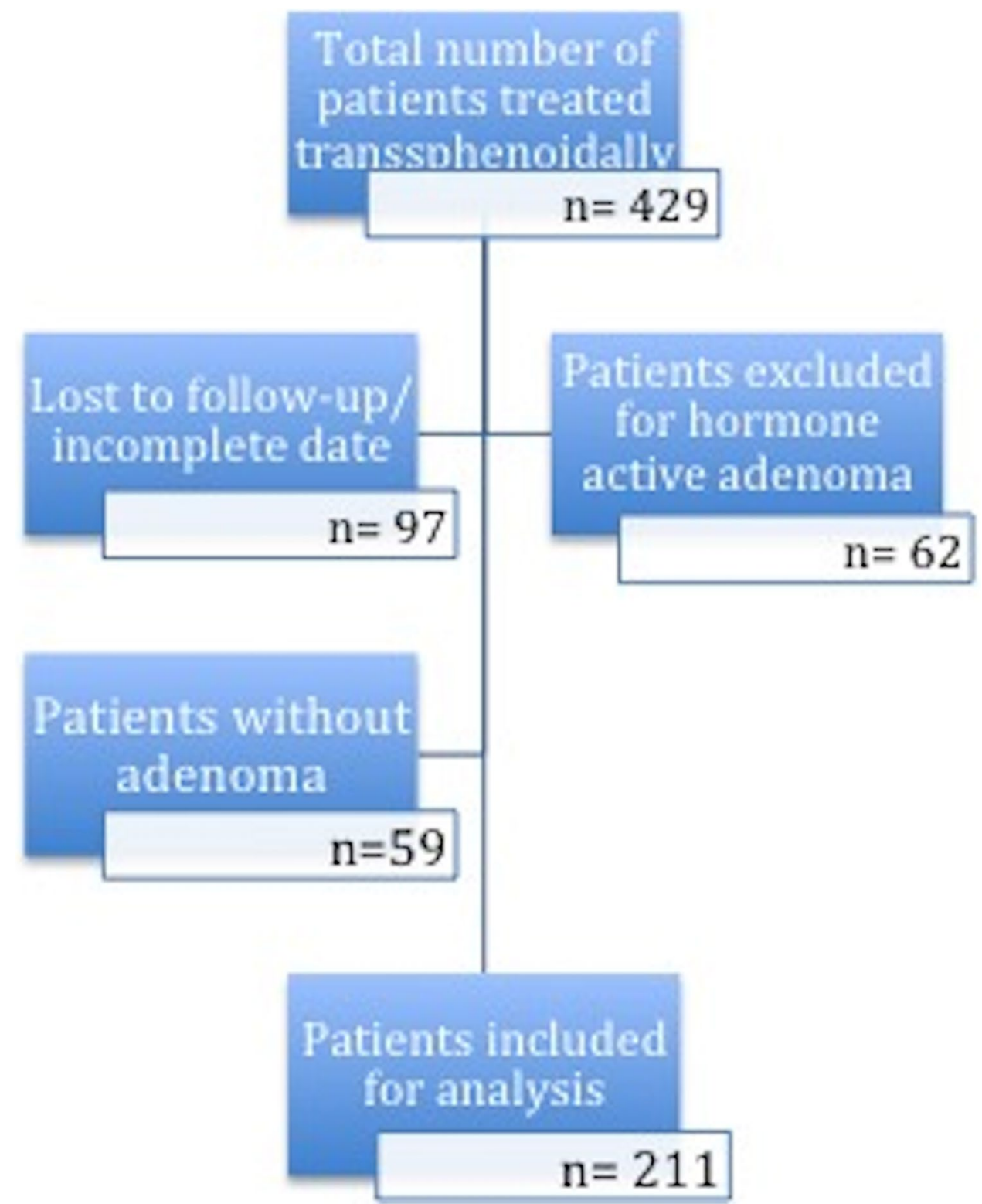


20-100\%). $97.6 \%$ of the patients suffered from pituitary macroadenoma, and only 5 patients presented with progressive hormone-inactive pituitary microadenoma (only selected cases such as patients presenting with tumor growth on follow-up imaging leading to the indication of surgical removal (2.4\%)).

\section{Hormone levels}

All patients were given intra- and postoperative hydrocortisone substitution according to the following standard scheme: patients obtained $50 \mathrm{mg}$ of intravenous hydrocortisone injection on induction, followed by immediate initiation of a continuous infusion of hydrocortisone $100 \mathrm{mg} / 24 \mathrm{~h}$. On postoperative day 1, patients obtained $80 \mathrm{mg}$ (infusion for $24 \mathrm{~h}$ ). On day 2 after surgery, we continued with an oral administration of $60 \mathrm{mg}$ hydrocortisone $(20 \mathrm{mg}$ in the morning, noon, and evening) with continuous reduction of $10 \mathrm{mg}$ per day until the maintenance dosage of $20 \mathrm{mg}$ per day (10 $\mathrm{mg}$ in the morning and at noon).

Table 1 describes the preoperative values, postoperative values, and long-term cortisol results after one year of patients grouped by hypocortisolism. Mean preoperative early morning cortisol level was $11.7 \mu \mathrm{g} / \mathrm{dl}$ (range 0.2 to $37.1 \mu \mathrm{g} / \mathrm{dl}$ ) and mean postoperative (5 days after TSS) level was $12.6 \mu \mathrm{g} / \mathrm{dl}$ (range 0.2 to $45.1 \mu \mathrm{g} / \mathrm{dl}$ ). At 6 weeks to 12 weeks, mean early morning cortisol level was $11.9 \mu \mathrm{g} /$ $\mathrm{dl}$ (range 0.1 to $59.8 \mu \mathrm{g} / \mathrm{dl}$ ) and long-term data (minimum 1-year follow-up) revealed a mean basal cortisol level of $11.2 \mu \mathrm{g} / \mathrm{dl}$ (range $0.1-35.1 \mu \mathrm{g} / \mathrm{dl}$ ).

If grouped by clinical hypocortisolism symptoms and need for hydrocortisone substitution, mean basal serum cortisol values in patients with hypocortisolism were $3.99 \mu \mathrm{g} /$ $\mathrm{dl}$ and $15.1 \mu \mathrm{g} / \mathrm{dl}$. Mean hormone levels of basal cortisol at long-term follow-up (minimum 1 year) were $6.01 \mu \mathrm{g} / \mathrm{dl}$ for patients with long-term need of hydrocortisone substitution and $13.7 \mu \mathrm{g} / \mathrm{dl}$ for the healthy counterpart without replacement therapy (Figs. 2 and 3, Table 1).

\section{Clinical and surgical outcome}

The overall clinical outcome showed satisfying postoperative results. Median postoperative KPS of our patients was $90 \%$ (range $40-100 \%$ ). Mean duration of surgery was
Table 1 Preoperative hormone levels classified by timing of the analysis and classified in patients with corticotroph deficiency and intact corticotroph function 5 days after surgery ("early postoperative"), 6 to

\begin{tabular}{|c|c|c|c|c|}
\hline Mean hormone level & Preoperative & Early postoperative & After 6-12 weeks & 1 year after surgery \\
\hline Basal cortisol ( $\mu \mathrm{g} / \mathrm{dl}) @(95 \% \mathrm{CI})$ & $\begin{array}{l}11.7 \\
(10.7-12.6)\end{array}$ & $\begin{array}{l}12.6 \\
(11.5-13.8)\end{array}$ & $\begin{array}{l}11.9 \\
(10.7-13.1)\end{array}$ & $\begin{array}{l}11.2 \\
(10.2-11.2)\end{array}$ \\
\hline In patients with hypocortisolism & $\begin{array}{l}3.99 \\
(3.2-4.8)\end{array}$ & $\begin{array}{l}8.6 \\
(6.5-10.7)\end{array}$ & $\begin{array}{l}7.7 \\
(5.4-9.8)\end{array}$ & $\begin{array}{l}6.01 \\
(4.2-7.8)\end{array}$ \\
\hline In patients without hypocortisolism & $\begin{array}{l}15.1 \\
(14.2-16.0)\end{array}$ & $\begin{array}{l}15.1 \\
(13.7-16.5)\end{array}$ & $\begin{array}{l}13.4 \\
(12.4-14.5)\end{array}$ & $\begin{array}{l}13.7 \\
(12.7-14.6)\end{array}$ \\
\hline
\end{tabular}

12 weeks after surgery and 1 year after surgery with 95\% CI (confidence interval)
Fig. 2 Distribution of basal cortisol levels depending on necessity of hydrocortisone substitution (0: no substitution, 1: hydrocortisone substitution) before surgery (in $\mu \mathrm{g} / \mathrm{dl}$ ) 
Fig. 3 Distribution of basal cortisol levels depending on necessity of hydrocortisone substitution (0: no substitution, 1: hydrocortisone substitution) 1 year after surgery (in $\mu \mathrm{g} / \mathrm{dl}$ )

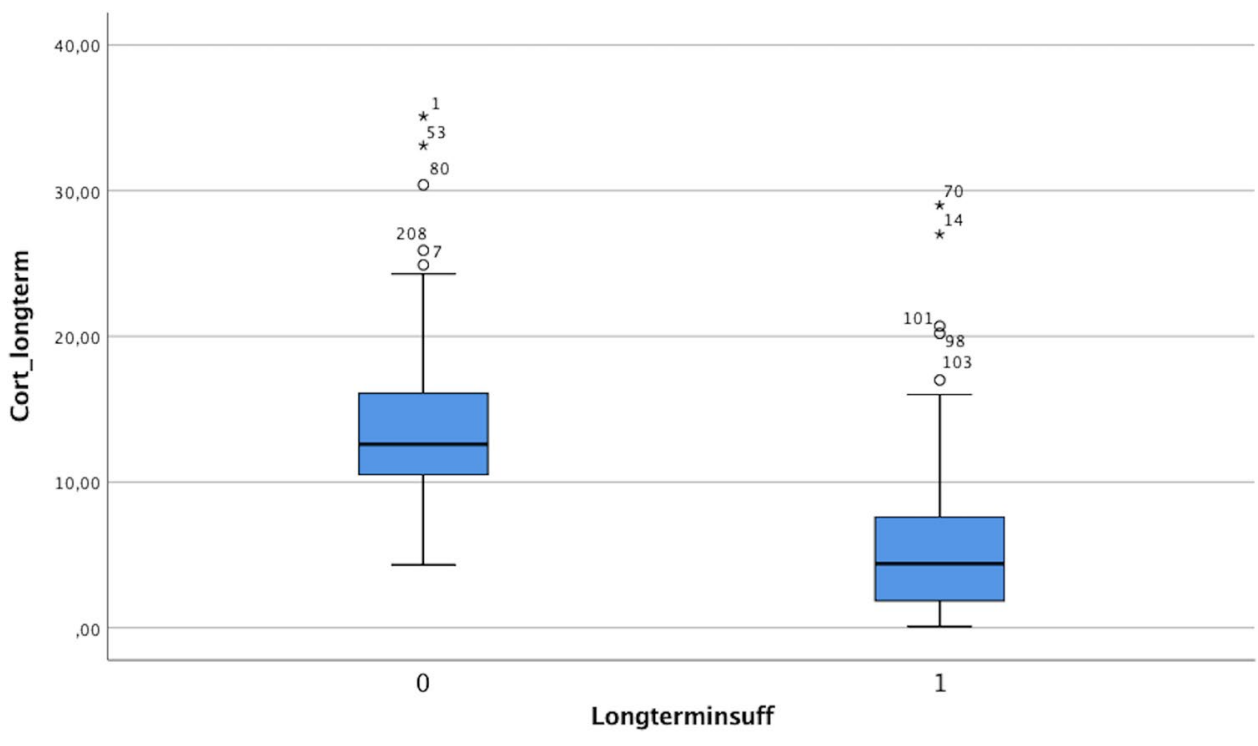

$84 \mathrm{~min}$, ranging from 24 to $489 \mathrm{~min}$. Of all performed surgeries, $68.1 \%$ of the TSS were performed with a microscope, and in $31.9 \%$ of the cases with a $0^{\circ}$ or $30^{\circ}$ endoscope. We did not identify any significant differences in terms of complications or clinical outcome between patients operated with the endoscope or microscopical approach.

Overall, perioperative complications occurred in $18 \%$ of the operated cases (occurrence of transient diabetes insipidus with the need for desmopressin substitution in $7.1 \%$, occurrence of an intraoperative dural tear with the need for postoperative surgical revision in $4.7 \%$, operative revision due to postoperative hemorrhage in three cases $1.4 \%$ ).

GTR was achieved in $79.1 \%$ (evaluated by analyzing the postoperative imaging and determined as no residual tumor detected on the postoperative MRI). Patients with residual (mostly suprasellar) tumor were advised to perform a followup MRI after 6-12 weeks. In cases with good access to the descended residual tumor, the patients underwent a second transnasal surgery.

\section{Cut-off values, sensitivity and specificity}

According to the receiver operator characteristic (ROC) curves, fasting serum cortisol levels analyzed 6 weeks to 3 months after surgery were more accurate in predicting long-term intact corticotroph function (area under the curve, AUC 0.808) compared to the directly postoperative assessed levels (AUC 0.740). Naturally, the AUC of long-term basal cortisol levels predicted the corticotroph function most appropriately (AUC 0.864) (Fig. 4).

The cut-off value for direct postoperative fasting serum cortisol level was $6.9 \mu \mathrm{g} / \mathrm{dl}$ (sensitivity $86.4 \%$, specificity $56 \%$, Youden-Index 0.424). For values measured after 6 to 12 weeks after surgery, the cut-off prognostic basal cortisol

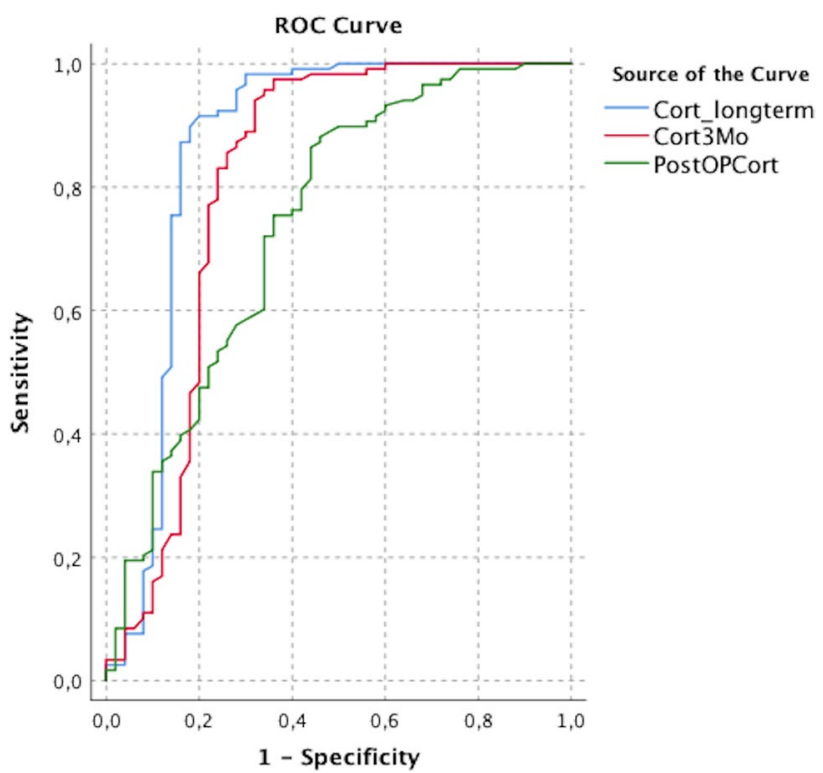

Fig. 4 Receiver operator characteristic (ROC) curve showing the sensitivity and specificity of direct postoperative basal cortisol level, 3 months postoperatively and long-term, indicating a higher sensibility and specificity of the long-term cortisol compared to the direct postoperative cortisol level

was $6.95 \mu \mathrm{g} / \mathrm{dl}$ with a sensibility of $94.1 \%$ and specificity of $68 \%$ (Youden-Index 0.621). Basal cortisol measured after at least one year after surgery had the highest prognostic power at a value of $8.35 \mu \mathrm{g} / \mathrm{dl}$ (sensitivity $90 \%$, specificity $82 \%$, Youden-Index 0.718) (Table 2). 
Table 2 Morning serum cortisol levels assessed on the fifth day after surgery (postoperative value), 6-12 weeks after surgery and one year after surgery

\begin{tabular}{llllll}
\hline $\begin{array}{l}\text { Cortisol morning serum } \\
\text { values (ug/dl) }\end{array}$ & $\begin{array}{l}\text { Normal pituitary function if } \\
\text { cortisol greater than or equal } \\
\text { to }\end{array}$ & Sensitivity & Specificity & Youden Index \\
\hline Postoperative value & 2.8 & $\mathbf{0 . 9 4 9}$ & 0.32 & 0.269 & \\
& $\mathbf{6 . 9}^{*}$ & 0.864 & 0.56 & 0.424 & \\
& 10.15 & 0.729 & 0.64 & 0.369 & \\
& 20.65 & 0.195 & $\mathbf{0 . 9 4}$ & 0.135 \\
6-12 weeks after surgery & 6.85 & $\mathbf{0 . 9 4 9}$ & 0.66 & 0.609 \\
& $\mathbf{6 . 9 5 *}$ & 0.941 & 0.68 & 0.621 \\
& 10.05 & 0.746 & 0.78 & 0.526 \\
& 20.3 & 0.085 & $\mathbf{0 . 9 4}$ & 0.025 & \\
& 7.05 & $\mathbf{0 . 9 4 9}$ & 0.72 & 0.669 \\
& $\mathbf{8 . 3 5 *}$ & 0.898 & 0.82 & 0.718 \\
& 10.05 & 0.805 & 0.84 & 0.645 \\
& 20.45 & 0.076 & $\mathbf{0 . 9 4}$ & 0.016 \\
\hline
\end{tabular}

The optimum cut-off value is marked*. The lower and higher cortisol value describes the $95 \%$ sensitivity and $95 \%$ specificity. The Youden index describes the maximum potential effectiveness of a certain cut-off value. Note that the described cut-off value determines the intact corticotropic function

Numbers in boldface determine the highest sensitivity or specificity

\section{Long-term corticotropic deficiency}

Long-term hydrocortisone replacement after 1 year was observed in $30.9 \%$ of the patients and in $30.4 \%$ of the patients before surgical treatment. Overall, $9 \%$ recovered from preoperative hypocortisolism and 10.4\% developed a new postoperative impaired HPA-axis leading to hypocortisolism. In total, $80.6 \%$ of our patients had no changes regarding the pituitary function (persistent hypocortisolism without recovery or intact function postoperatively in patients without preoperative hypocortisolism).

In $14.6 \%$, the postoperative cortisol level was above the measured threshold of $6.9 \mu \mathrm{g} / \mathrm{dl}$ while patients still suffered from long-term hypocortisolism (false negative patients). False positive results occurred in $11.1 \%$ of the cases with our assessed direct postoperative cortisol cut-off value of $6.9 \mu \mathrm{g} / \mathrm{dl}$ (hydrocortisone substitution in patients with potentially intact HPA-axis). In total, regarding that all patients had a hydrocortisone replacement for safety reasons until the first endocrinological follow-up 6 weeks to 3 months after surgery, $66.3 \%$ of the patients underwent substitution while having a basal postoperative cortisol level above the determined threshold.

\section{Prognostic factors}

Gender, age, year of operation, GTR, and preoperative KPS did not significantly influence the occurrence of a new postoperative hypocortisolism $(p>0.05)$. The occurrence of complications significantly increased the risk for a new postoperative corticotroph deficiency ( $\mathrm{r}, 0.281 ; p<0.01$, OR 4.4 , overall long-term hypocortisolism OR $2.7, p 0.006$ ) and the postoperative clinical outcome in terms of KPS (KPS, $\mathrm{r},-0.165 ; p 0.018)$.

\section{Discussion}

Compared to current literature, a new onset of hypocortisolism is described in approximately $2 \%$ up to $10 \%[4,9$, $11,23,35]$, depending on the surgical approach which is consistent with our presented results.

Long-term hypocortisolism requiring substitution with hydrocortisone occurred in $30.9 \%$ of all cases; in $10.4 \%$, the deficiency was new, and $9 \%$ of the patients with preoperative hypocortisolism had intact pituitary hormone secretion at follow-up of minimum 1 year.

Our results show a higher rate of postoperative improvement of preoperative manifest hypocortisolism, as current literature reports of a laboratory normalization of 3\% after 6 months for the cortisol axis. We also identified a higher rate of new hypocortisolism compared to the stated $6 \%$ of new postoperative hypocortisolism in current literature [20]. Compared to other tumors of the sellar regions, these percentages seem very low (craniopharyngiomas: up to $53 \%$ of postoperative hypocortisolism after TSS [26], and rate of hypocortisolism after resection of Rathke's cleft cyst, $24 \%$ [25]). As these tumors were excluded from the analysis, no comparison between current literature and our 
results can be made concerning other sellar tumors than pituitary adenoma.

\section{Limitations}

Our study analyzed patients retrospectively, but complete long-term follow up data was available for a considerably large series of 211 patients. Unfortunately, the burden of disease caused by long-term hormone substitution has not been evaluated yet and was not included in our data examination. Symptoms of hypocortisolism, such as fatigue and impairment of daily living activities [14], are therefore not stated or described in our study. Therefore, we cannot assess the overall burden of disease caused by the transnasal surgical resection of pituitary adenoma. We unfortunately did not evaluate the subjective disability experienced and the prospective assessment of quality of life and impairment of daily living activities would give beneficial information on the overall treatment benefit or risks for patients treated surgically for pituitary adenoma [14].

Furthermore, patients were only included and analyzed, if complete endocrinological and clinical follow-up data was available. A bias is therefore included and needs to be discussed, potentially including more patients with complications and postoperative deficiencies in the analysis because of their increased need of postoperative supervision and follow-up appointments. Therefore, the evaluated $10 \%$ rate of new postoperative hypocortisolism is most probably overrated in our patient cohort.

As we aimed to focus on hypocortisolism, we did not assess other pituitary deficiencies such as the often-frequented hypogonadism in male patients which presents a limitation of our study.

We performed a purely retrospective analysis, and patients describing symptoms of hypocortisolism after hydrocortisone withdrawal were continued on hydrocortisone substitution without further assessment, based on the assumption that ACTH testing may not detect cases of newonset secondary adrenal insufficiency $[7,10]$. The uncertainty around the clinical and the laboratory investigation of hypocortisolism remains a strong limitation of our study.

\section{Cut-off values and timing of analysis}

While detection of intact corticotroph function is of main interest to prevent Addison's crisis, we found different values for the sensitivity and specificity of laboratory cortisol testing direct postoperatively, 6-12 weeks after surgical treatment and 1 year after surgery. Of course, the closer the laboratory analysis coincides with the long-term followup clinical examination, the more sensitive and specific it becomes as some patients recover from postoperative hormone deficiencies and some patients tend to develop a secondary hypocortisolism. Our main interest is therefore to question the use of direct postoperative basal cortisol assessment if its use is very limited.

\section{Prediction of long-term corticotropic deficiency}

The exact cut-off value of cortisol serum levels to determine hypocortisolism and its appropriate timing of testing (laboratory value measured in $\mu \mathrm{g} / \mathrm{dl}$ in morning serum) is still matter of debate $[6,24,38]$. Published cut-off values range between $4 \mu \mathrm{g} / \mathrm{dl}$ [21], $8 \mu \mathrm{g} / \mathrm{dl}$ [6], and $14 \mu \mathrm{g} / \mathrm{dl}$ [21]. In our study, we classified patients based on their actual clinical need of hydrocortisone substitution regardless of their serum cortisol levels, which may over- or underestimate the real fraction of patients suffering from hypocortisolism due to false interpretation symptoms such as fatigue. The measured and assessed cortisol cut-off value of $8.35 \mu \mathrm{g} / \mathrm{dl}$ is congruent with and within the range of published data. Patients with basal serum cortisol levels above $>10 \mu \mathrm{g} / \mathrm{dl}$ were declared as "hypocortisolism" if they still presented with symptoms of hypocortisolism and had the clinical need for hydrocortisone supplementation when the hydrocortisone administration was reduced (mostly symptoms of fatigue). False high basal cortisol levels due to either ingestion of hydrocortisone before blood testing ( $24 \mathrm{~h}$ off replacement hydrocortisone) or even factitious ingestion of hydrocortisone [1] were tried to be accounted for but cannot be excluded completely and may increase the uncertainty around a specific "cut-off" value for intact corticotroph function. Values from patients stating they had their hydrocortisone medication or food/ coffee intake before the blood was taken were of course excluded from analysis.

In our department, hydrocortisone supplementation is usually continued for 6 to 12 weeks after transsphenoidal surgery until the following endocrine laboratory testing, regardless of the assessed postoperative cortisol serum values. Side effects of supplementary (unnecessary) hydrocortisone administration could be prevented if the post-operative basal cortisol level or timing was more reliable and as early as possible, and direct postoperative testing obsolete if the positive predictive value is inferior to the long-term testing. Unfortunately, we did not assess possible consequences of supplementary (over-substituted) hydrocortisone substitution in terms of possible side effects such as high blood pressure, diabetic complications, or osteoporosis [36]. In order to assess the complete impact of false hydrocortisone administration, a prospective analysis of patients suffering from pituitary adenoma would be necessary, with a close attention to signs of under- or over-supplementation. Neither did we assess economic differences in term of cost-effectiveness of early versus late assessment of serum cortisol values and correct hydrocortisone substitution. 
In total $66.3 \%$ if the patients underwent hydrocortisone substitution (substitution dosage of $10 \mathrm{mg}$ administered in the morning and midday for 6 weeks) while having intact postoperative pituitary function using our defined cut-off value. The use of direct postoperative cortisol level evaluation has previously been questioned regarding its utility in clinical practice and implication for further hydrocortisone substitution [16, 19, 30, 32]. With the risk of Addison's disease, some patient may be rather over-supplemented, with the risk of long-term effects of hypercortisolism [34]. Therefore, reliable cut-off values with a high positive predictive value and an optimal timing of analysis need to be provided. In out department, we shifted towards a more individual approach focusing on patients with very low postoperative cortisol levels and higher levels to present in our outpatient department earlier in order to adjust or stop the hydrocortisone substitution. We furthermore abandoned the strict cortisol cut-off value of $10 \mathrm{ug} / \mathrm{dl}$ and focus more on the clinical and functional status of the patient after with-drawing the hydrocortisone substitution. Nevertheless, the higher mortality caused by hypocortisolism [12] compared to risks caused by over-supplementation of hydrocortisone may shift the optimal early cut-off value for basal cortisol towards a higher sensibility at the cost of a lower specificity.

Hypocortisolism may be caused by surgery related injury of the pituitary gland, but also due to long-term administration of corticoids. In our cohort population, patients obtained only $20 \mathrm{mg}$ of oral hydrocortisone per day, which is usually below the threshold causing HPA suppression [22]. Only one patient was given prednisolone for rheumatoid arthritis prior to pituitary surgery and was therefore excluded from the analysis.

\section{Conclusion}

In $30.9 \%$ of all patients, long-term hydrocortisone substitution was necessary to support the adrenocorticotropic axis in patients with hypocortisolism. Prediction of hormone production, especially hypocortisolism, remains an important matter of debate in the neurooncological context; the duration of hydrocortisone substitution and timing of evaluation should therefore be questioned. In our study, evaluated cut-off values were congruent with published literature, and substitution in patients with intact postoperative pituitary function should be discussed further to reduce the risk of potential side effects. An improvement in reliability and prognostic quality of laboratory testing may reduce hydrocortisone oversupply without increasing the amount of undetected postoperative hypocortisolism.
Author contribution VB, NS, AW, and VS made substantial contributions to conception and design, or acquisition of data, or analysis and interpretation of data; VB has been involved in drafting the manuscript; JG has been involved in revising it critically for important intellectual content; JG, SB, and BM given final approval of the version to be published. VB and JG agreed to be accountable for all aspects of the work in ensuring that questions related to the accuracy or integrity of any part of the work are appropriately investigated and resolved.

Funding Open Access funding enabled and organized by Projekt DEAL.

Data availability The datasets used and/or analyzed during the current study are available from the corresponding author on reasonable request.

Code availability Not applicable.

\section{Declarations}

Ethics approval The research conducted has been performed in accordance with the Declaration of Helsinki, ethics approval was obtained, and the positive vote was registered under the number 231/20-S.

Consent to participate and consent for publication Informed consent for publication and surgical treatment was obtained.

Conflict of interest The authors declare no competing interests.

Open Access This article is licensed under a Creative Commons Attribution 4.0 International License, which permits use, sharing, adaptation, distribution and reproduction in any medium or format, as long as you give appropriate credit to the original author(s) and the source, provide a link to the Creative Commons licence, and indicate if changes were made. The images or other third party material in this article are included in the article's Creative Commons licence, unless indicated otherwise in a credit line to the material. If material is not included in the article's Creative Commons licence and your intended use is not permitted by statutory regulation or exceeds the permitted use, you will need to obtain permission directly from the copyright holder. To view a copy of this licence, visit http://creativecommons.org/licenses/by/4.0/.

\section{References}

1. Anfinson TJ, Channappa C, Vo HT (2008) Drug dependence involving prednisone: two cases and a review of the literature. Psychopharmacol Bull 41:154-163

2. Arlt W, Rosenthal C, Hahner S, Allolio B (2006) Quality of glucocorticoid replacement in adrenal insufficiency: clinical assessment vs. timed serum cortisol measurements. Clin Endocrinol (Oxf) 64:384-389. https://doi.org/10.1111/j.1365-2265. 2006.02473.x

3. Auchus RJ, Shewbridge RK, Shepherd MD (1997) Which patients benefit from provocative adrenal testing after transsphenoidal pituitary surgery? Clin Endocrinol (Oxf) 46:21-27

4. Berker M, Hazer DB, Yücel T, Gürlek A, Cila A, Aldur M, Onerci M (2012) Complications of endoscopic surgery of the pituitary adenomas: analysis of 570 patients and review of the literature. Pituitary 15:288-300. https://doi.org/10.1007/s11102-011-0368-2

5. Cohen-Gadol AA, Liu JK, Laws ER (2005) Cushing's first case of transsphenoidal surgery: the launch of the pituitary surgery 
era. J Neurosurg 103:570-574. https://doi.org/10.3171/jns.2005. 103.3.0570

6. Courtney CH, McAllister AS, McCance DR, Bell PM, Hadden DR, Leslie H, Sheridan B, Atkinson AB (2000) Comparison of one week $0900 \mathrm{~h}$ serum cortisol, low and standard dose synacthen tests with a 4 to 6 week insulin hypoglycaemia test after pituitary surgery in assessing HPA axis. Clin Endocrinol (Oxf) 53:431-436. https://doi.org/10.1046/j.1365-2265.2000.01106.x

7. de Vries F, Lobatto DJ, Bakker LEH, van Furth WR, Biermasz NR, Pereira AM (2020) Early postoperative HPA-axis testing after pituitary tumor surgery: reliability and safety of basal cortisol and CRH test. Endocrine 67:161-171. https://doi.org/10. 1007/s12020-019-02094-6

8. Diri H, Ozaslan E, Kurtsoy A, Tucer B, Simsek Y, Ozturk F, Durak AC, Bayram F (2014) Prognostic factors obtained from long-term follow-up of pituitary adenomas and other sellar tumors. Turk Neurosurg 24:679-687. https://doi.org/10.5137/ 1019-5149.JTN.9140-13.1

9. Do H, Kshettry VR, Siu A, Belinsky I, Farrell CJ, Nyquist G, Rosen M, Evans JJ (2017) Extent of resection, visual, and endocrinologic outcomes for endoscopic endonasal surgery for recurrent pituitary adenomas. World Neurosurg 102:35-41. https://doi.org/10.1016/j.wneu.2017.02.131

10. Dokmetas HS, Colak R, Kelestimur F, Selcuklu A, Unluhizarci K, Bayram F (2000) A comparison between the 1-microg adrenocorticotropin (ACTH) test, the short ACTH (250 microg) test, and the insulin tolerance test in the assessment of hypothalamo-pituitaryadrenal axis immediately after pituitary surgery. J Clin Endocrinol Metab 85:3713-3719. https://doi.org/10.1210/jcem.85.10.6879

11. Duz B, Harman F, Secer HI, Bolu E, Gonul E (2008) Transsphenoidal approaches to the pituitary: a progression in experience in a single centre. Acta Neurochir (Wien) 150:1133-1138; discussion 1138-1139. https://doi.org/10.1007/s00701-008-0135-y

12. Hahner S (2018) Acute adrenal crisis and mortality in adrenal insufficiency: still a concern in 2018! Ann Endocrinol (Paris) 79:164-166. https://doi.org/10.1016/j.ando.2018.04.015

13. Hindmarsh PC, Charmandari E (2015) Variation in absorption and half-life of hydrocortisone influence plasma cortisol concentrations. Clin Endocrinol (Oxf) 82:557-561. https://doi.org/ $10.1111 /$ cen. 12653

14. Ho W, Druce M (2018) Quality of life in patients with adrenal disease: a systematic review. Clin Endocrinol (Oxf) 89:119_ 128. https://doi.org/10.1111/cen.13719

15. Hong GK, Payne SC, Jane JA (2016) Anatomy, physiology, and laboratory evaluation of the pituitary gland. Otolaryngol Clin $\mathrm{N}$ Am 49:21-32. https://doi.org/10.1016/j.otc.2015.09.002

16. Hout WM, Arafah BM, Salazar R, Selman W (1988) Evaluation of the hypothalamic-pituitary-adrenal axis immediately after pituitary adenomectomy: is perioperative steroid therapy necessary? J Clin Endocrinol Metab 66:1208-1212. https://doi.org/10.1210/ jcem-66-6-1208

17. Inder WJ, Hunt PJ (2002) Glucocorticoid replacement in pituitary surgery: guidelines for perioperative assessment and management. J Clin Endocrinol Metab 87:2745-2750. https://doi.org/10.1210/ jcem.87.6.8547

18. Inder WJ, Meyer C, Hunt PJ (2015) Management of hypertension and heart failure in patients with Addison's disease. Clin Endocrinol (Oxf) 82:789-792. https://doi.org/10.1111/cen.12592

19. Jackanich A, Tavakol S, Strickland BA, Rutkowski M, Kamel D, Carmichael JD, Weiss M, Zada G (2019) Clinical utility of routine postoperative morning cortisol monitoring in detecting new hypothalamic-pituitary-adrenal axis insufficiency following endoscopic transsphenoidal surgery for sellar lesions. J Neurosurg:1-5. https://doi.org/10.3171/2018.11.JNS182521

20. Jahangiri A, Wagner JR, Han SW, Tran MT, Miller LM, Chen R, Tom MW, Ostling LR, Kunwar S, Blevins L, Aghi MK (2016)
Improved versus worsened endocrine function after transsphenoidal surgery for nonfunctional pituitary adenomas: rate, time course, and radiological analysis. J Neurosurg 124:589-595. https://doi.org/10.3171/2015.1.JNS141543

21. Jayasena CN, Gadhvi KA, Gohel B, Martin NM, Mendoza N, Meeran K, Dhillo WS (2009) Day 5 morning serum cortisol predicts hypothalamic-pituitary-adrenal function after transsphenoidal surgery for pituitary tumors. Clin Chem 55:972-977. https:// doi.org/10.1373/clinchem.2008.117374

22. Joseph RM, Hunter AL, Ray DW, Dixon WG (2016) Systemic glucocorticoid therapy and adrenal insufficiency in adults: a systematic review. Semin Arthritis Rheum 46:133-141. https://doi. org/10.1016/j.semarthrit.2016.03.001

23. Juraschka K, Khan OH, Godoy BL, Monsalves E, Kilian A, Krischek B, Ghare A, Vescan A, Gentili F, Zadeh G (2014) Endoscopic endonasal transsphenoidal approach to large and giant pituitary adenomas: institutional experience and predictors of extent of resection. J Neurosurg 121:75-83. https://doi.org/10. 3171/2014.3.JNS131679

24. Karaca Z, Tanriverdi F, Atmaca H, Gokce C, Elbuken G, Selcuklu A, Unluhizarci K, Kelestimur F (2010) Can basal cortisol measurement be an alternative to the insulin tolerance test in the assessment of the hypothalamic-pituitary-adrenal axis before and after pituitary surgery? Eur J Endocrinol 163:377-382. https://doi.org/ 10.1530/EJE-10-0229

25. Kasperbauer JL, Orvidas LJ, Atkinson JL, Abboud CF (2002) Rathke cleft cyst: diagnostic and therapeutic considerations. Laryngoscope 112:1836-1839. https://doi.org/10.1097/00005 537-200210000-00024

26. Li X, Wu W, Miao Q, He M, Zhang S, Zhang Z, Lu B, Yang Y, Shou X, Li Y, Wang Y, Ye H (2019) Endocrine and metabolic outcomes after transcranial and endoscopic endonasal approaches for primary resection of craniopharyngiomas. World Neurosurg 121:e8-e14. https://doi.org/10.1016/j.wneu.2018.08.092

27. Liu JK, Cohen-Gadol AA, Laws ER, Cole CD, Kan P, Couldwell WT (2005) Harvey Cushing and Oskar Hirsch: early forefathers of modern transsphenoidal surgery. J Neurosurg 103:1096-1104. https://doi.org/10.3171/jns.2005.103.6.1096

28. Loyo-Varela M, Ayala-Ruiz AR, Manrique-Guzman S (2013) Cortisol levels as predictors of short- and long-term adrenal function after endonasal transsphenoidal surgery for pituitary adenomas and Rathke's cleft cyst. World Neurosurg 80:493-494. https://doi. org/10.1016/j.wneu.2012.10.039

29. Marko NF, Weil RJ (2011) A comparative effectiveness analysis of alternative strategies to assess hypothalamic-pituitary-adrenal axis function after microsurgical resection of pituitary tumors. Neurosurgery 68:1576-1584; discussion 1585. https://doi.org/10. 1227/NEU.0b013e31820cd45a

30. Marko NF, Gonugunta VA, Hamrahian AH, Usmani A, Mayberg MR, Weil RJ (2009) Use of morning serum cortisol level after transsphenoidal resection of pituitary adenoma to predict the need for long-term glucocorticoid supplementation. J Neurosurg 111:540-544. https://doi.org/10.3171/2008.12.JNS081265

31. Marko NF, Hamrahian AH, Weil RJ (2010) Immediate postoperative cortisol levels accurately predict postoperative hypothalamicpituitary-adrenal axis function after transsphenoidal surgery for pituitary tumors. Pituitary 13:249-255. https://doi.org/10.1007/ s11102-010-0227-6

32. McLaughlin N, Cohan P, Barnett P, Eisenberg A, Chaloner C, Kelly DF (2013) Early morning cortisol levels as predictors of short-term and long-term adrenal function after endonasal transsphenoidal surgery for pituitary adenomas and Rathke's cleft cysts. World Neurosurg 80:569-575. https://doi.org/10.1016/j. wneu.2012.07.034

33. Michels A, Michels N (2014) Addison disease: early detection and treatment principles. Am Fam Physician 89:563-568 
34. Morin C, Fardet L (2015) Systemic glucocorticoid therapy: risk factors for reported adverse events and beliefs about the drug. A cross-sectional online survey of 820 patients. Clin Rheumatol 34:2119-2126. https://doi.org/10.1007/s10067-015-2953-7

35. Neal JG, Patel SJ, Kulbersh JS, Osguthorpe JD, Schlosser RJ (2007) Comparison of techniques for transsphenoidal pituitary surgery. Am J Rhinol 21:203-206

36. Nicolaides NC, Pavlaki AN, Maria Alexandra MA, Chrousos GP (2000) Glucocorticoid Therapy and adrenal suppression. In: Feingold KR, Anawalt B, Boyce A et al. (eds) Endotext. South Dartmouth (MA)

37. Okinaga H, Matsuno A, Okazaki R (2005) High risk of osteopenia and bone derangement in postsurgical patients with craniopharyngiomas, pituitary adenomas and other parasellar lesions. Endocr J 52:751-756. https://doi.org/10.1507/endocrj.52.751

38. Polovina TS, Kraljevic I, Solak M, Balasko A, Haxhiu A, Haxhiu A, Dusek T, Poljicanin T, Kastelan D (2019) Early basal cortisol level as a predictor of hypothalamic-pituitary-adrenal (HPA) axis function after pituitary tumor surgery. Exp Clin Endocrinol Diabetes. https://doi.org/10.1055/a-0885-1568

39. Saeger W, Lüdecke DK, Buchfelder M, Fahlbusch R, Quabbe HJ, Petersenn S (2007) Pathohistological classification of pituitary tumors: 10 years of experience with the German Pituitary Tumor Registry. Eur J Endocrinol 156:203-216. https://doi.org/10.1530/ eje.1.02326

40. Szerlip NJ, Zhang YC, Placantonakis DG, Goldman M, Colevas KB, Rubin DG, Kobylarz EJ, Karimi S, Girotra M, Tabar V (2011) Transsphenoidal resection of sellar tumors using high-field intraoperative magnetic resonance imaging. Skull Base 21:223232. https://doi.org/10.1055/s-0031-1277262

41. Takeuchi K, Nagatani T, Okumura E, Wakabayashi T (2014) A novel method for managing water and electrolyte balance after transsphenoidal surgery: preliminary study of moderate water intake restriction. Nagoya J Med Sci 76:73-82

42. Thapar K, Kovacs K, Laws ER (1995) The classification and molecular biology of pituitary adenomas. Adv Tech Stand Neurosurg 22:3-53

43. Tohti M, Li J, Zhou Y, Hu Y, Yu Z, Ma C (2015) Is peri-operative steroid replacement therapy necessary for the pituitary adenomas treated with surgery? A systematic review and meta analysis. PLoS ONE 10:e0119621. https://doi.org/10.1371/journal.pone. 0119621

44. Villwock JA, Villwock MR, Goyal P, Deshaies EM (2015) Current trends in surgical approach and outcomes following pituitary tumor resection. Laryngoscope 125:1307-1312. https://doi.org/ 10.1002/lary.25120

45. Vrionis FD, Saatman D, Sorenson J, Brem S (2002) Microscopic paraseptal sphenoidotomy approach for pituitary tumors. Cancer Control 9:223-231

46. Yin J, Tian L (2014) Joint confidence region estimation for area under ROC curve and Youden index. Stat Med 33:985-1000. https://doi.org/10.1002/sim.5992

Publisher's note Springer Nature remains neutral with regard to jurisdictional claims in published maps and institutional affiliations. 